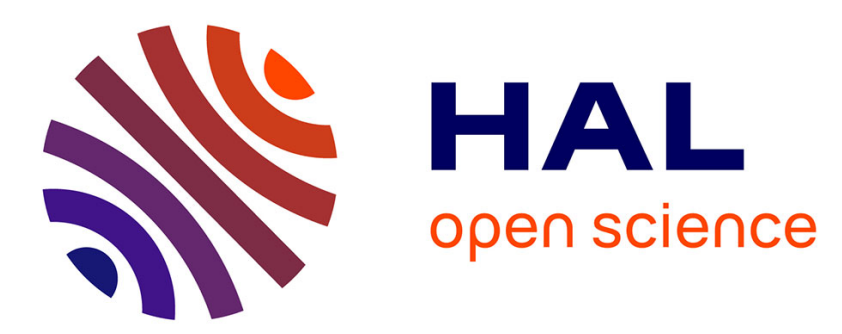

\title{
Perception and evaluation of noise sources in open plan office
}

\author{
Marjorie Pierrette, Etienne Parizet, Patrick Chevret
}

\section{To cite this version:}

Marjorie Pierrette, Etienne Parizet, Patrick Chevret. Perception and evaluation of noise sources in open plan office. International Congress on Acoustics 2013, 2013, Montréal, Canada. 4pNSa7. hal00994684

\section{HAL Id: hal-00994684 \\ https://hal.science/hal-00994684}

Submitted on 22 May 2014

HAL is a multi-disciplinary open access archive for the deposit and dissemination of scientific research documents, whether they are published or not. The documents may come from teaching and research institutions in France or abroad, or from public or private research centers.
L'archive ouverte pluridisciplinaire HAL, est destinée au dépôt et à la diffusion de documents scientifiques de niveau recherche, publiés ou non, émanant des établissements d'enseignement et de recherche français ou étrangers, des laboratoires publics ou privés. 


\title{
Proceedings of Meetings on Acoustics
}
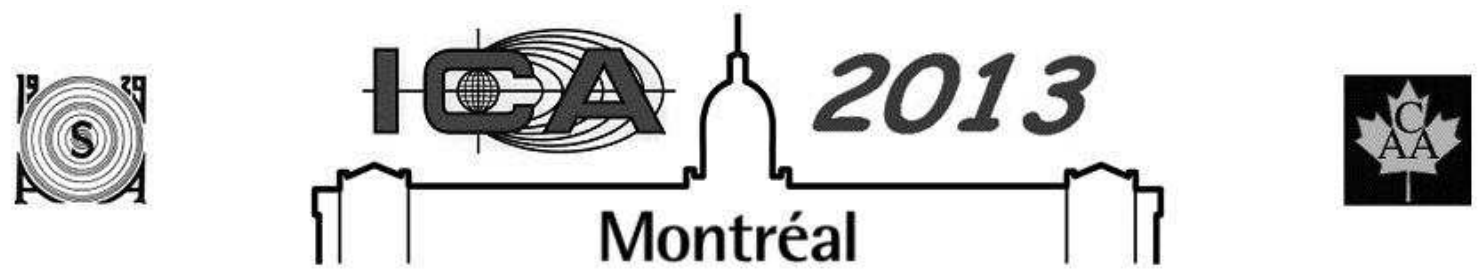

\author{
ICA 2013 Montreal \\ Montreal, Canada
}

2 - 7 June 2013

Noise

Session 4pNSa: Effects of Noise on Human Performance and Comfort II

\section{4pNSa7. Perception and evaluation of noise sources in open plan office}

Marjorie Pierrette*, Etienne Parizet and Patrick Chevret

*Corresponding author's address: Laboratoire Vibrations Acoustiques, INSA, Villeurbanne, 69621, Rhône-Alpes, France, marjorie.pierrette@insa-lyon.fr

Open plan offices are now the most common form of workspaces organisation. They can improve communication between workers while saving space. Their main drawbacks are the lack of intimacy for occupants and the increase of noise level. Noise is one of the most important annoyance factor as described by workers (see SBISB study, 2010). This paper describes a study aiming at a better knowledge of most annoying noise sources in an open plan offices. It consisted in interviews and questionnaires conducted in offices together with physical measurement. This provided some information about sources and tasks for which workers are mainly disturbed. The analysis of recorded answers allowed to evaluate the influence of this annoyance on job stress and health and emphasize the influence of environmental and individual factors in the assessment of noise annoyance.

Published by the Acoustical Society of America through the American Institute of Physics 


\section{INTRODUCTION}

The open-plan office concept was developed by two German consultants, Eberhard and Wolfgang Schennel, in the 1950s. Today this kind of workspace is the most common one among companies in all business sectors. These offices are open to improve communication between colleagues and thus to facilitate teamworking while saving space. However, it appears nowadays that noise is a major annoyance factor in open offices (SBiB, 2010), in spite of a low level (less than $65 \mathrm{~dB}(\mathrm{~A})$, see Landström et al. 1995). Therefore, noise level regulations failed in describing noise annotance in such offices. In the mean time, it seems that annoyance felt toward noise in open spaces has consequences on job satisfaction (Leather et al., 2003), on the health of employees (Pejtersen et al., 2006), and that this noise exposure can reduce performances of the employees according to the types of tasks to be carried out and the characteristics of noises present in the workplace (Beaman, 2005).

According to the European Commission (2000), "annoyance is a term used to describe the negative feelings associated with noise". Lindvall and Radford (1973), insisting on its subjective aspect, defined it as an "unpleasant feeling associated with an agent or condition that may affect an individual or group". That is why noise level on its own cannot fully explain annoyance. For example, factors like source of noise (Jensen et al., 2005), sensitivity level (Miedema and Vos, 1998), feeling of control (Glass, Reim and Singer, 1971), and gender (Kjellberg, Landström, Tesarz, Söderberg, and Akerlund, 1996) can modulate the annoyance feeling.

\section{OBJECTIVES}

This research aims to assess the physical environment of open workspaces through an in-situ survey. More specifically, we want :

- $\quad$ to know how employees evaluate their sound environment at workspace;

- to identify the different sources of noise presents in the workspace;

- to estimate the most annoying noise sources.

We also want to evaluate the tasks for which people declare themselves particularly disturbed and to measure the impact of this annoyance on job stress and employee's health. Finally, we want to see if sociodemographic factors (age, sex, status within the company, seniority, etc...), environmental ones (physical and organizational) or individual ones (noise sensitivity) can modulate the level of noise annoyance felt.

\section{METHODOLOGY}

Several thematics relative to the objectives of the research are addressed in the questionnaire. Thus, we discuss satisfaction with the workspace, the various noises present at the workplace (frequency of perception, annoyance felt, and impact on work), the perceived physical and moral health of respondents and some personal factors (age, sex, level of sensitivity to noise) and contextual factors (length of service) which may have an influence on the noise annoyance.

\section{Satisfaction with the Workspace}

We have chosen to use the satisfactory scale with the work environment developed by Fleury-Bahi and Marcouyeux (2011). It is a bifactorial scale which evaluates satisfaction at work with two dimensions: Control/Privacy and Comfort/Functionality. These two dimensions, as well as the general appreciation have a level of internal consistency quite satisfactory $(\alpha=.84$ for the general factor, $\alpha=.78$ for dimension control / Privacy and $\alpha=.77$ for the dimension comfort / functionality). This scale can be used with participants practicing their profession in different areas. The proposed measure is an easy-to-use and short questionnaire (12 items). People are invited to answer each question on a 5-point scale ranging from 1 to 5 ( 1 is "Not at all satisfactory" and 5 is "quite satisfactory"). This scale enables to calculate a general score of environmental satisfaction at work and two other scores of Control/Privacy and Comfort/functionality. 


\section{Assessment of Environmental Noise}

First, the general noise intensity and annoyance are evaluated with two 5-point scale ranging from 1 to 5 ( 1 is "not at all" and 5 is "totally").

A second part, we evaluate specific noises present on environmental workspace like office machinery, telephones ringing, people talking, and people who pass. These specific noises are evaluated according to the frequency of perception of the quoted noises, the level of annoyance that each noise involves. Then people should say for each noise presented if they are disturbed and for what kind of activity.

Finally, we asked participants to rank seven noise environment elements according to their level of annoyance: office machinery, telephones ringing, people talking but you don't understand conversation), people talking and you can understand totally conversation), people who pass, noise associated with people (keyboard, opening and closing of drawers, etc.), and noise associated with specific person.

\section{Perceived Physical and Mental Health}

Items about physical and mental health come from SATIN questionnaire developed and validated by Grosjean, Kop, Formet-Robert and Althaus (2012). These items can lead to the calculation of an overall score of perceived health and four specific scores: physiological and psychological health perceived, symptoms and stress. Scores range between 1 and 5. Scores close to 1 indicate a very poor health, while scores close to 5 indicate a very satisfactory state. The scale has a good internal consistency $(\alpha=.93$ for perceived physical health, $\alpha=.83$ for perceived stress, $\alpha=.81$ for perceived symptoms, $\alpha=.80$ for perceived mental health).

\section{Personal factors}

Personal factors are gender, age and noise sensitivity. We have chosen to evaluate noise sensitivity with the short version of Noise Sensitivity Questionnaire (NOISEQ) developed by Schutte, Marks, Wenning, and Griefahn (2007) and validated (Schutte, Sandrock, and Griefahn, 2007). The short version (NOISEQ-R) included 3 subscales (sleep, home, work) with 4 items by subscales so 12 questions in all. The short version was tested (Griefahn, 2008) and showed good internal consistency $(\alpha=0.87)$.

\section{Contextual factors}

Contextual factors are, for the majority, open's questions regarding to the status within the company, length of service in the company and at this post, if it is a fixed work station and number of people working in the open office.

\section{RESULTS}

All the results of this study will be presented at the conference.

Descriptive statistics will be presented concerning annoyance level felt for each noise to identify the most annoying noise sources. We will present also tasks for which people declare themselves particularly disturbed by noise.

We will measure the impact of noise annoyance level on job stress and employee's health.

We will assessed if sociodemographic factors (age, sex, status within the company, seniority, etc...), environmental ones (physical and organizational) or individual ones (noise sensitivity) can modulate the level of noise annoyance felt.

\section{ACKNOWLEDGMENTS}

This project is funded by ANSES (Agence nationale de sécurité sanitaire, de l'alimentation, de l'environnement et du travail), in the frame of the Environment-Health-Work Program, with the support of Governmental Offices for Environment and Work. 


\section{REFERENCES}

Beaman, P. (2005). "Auditory distraction from low-intensity noise: A review of the consequences for learning and workplace environments,” Appl. Cogn. Psychol. 19, 1041-1064.

Etude SBiB (2010). "Enquête Suisse dans les bureaux," 159 p.

European Commission (2000). "European commission position paper on EU noise indicators," 92-828-8953-X Office for Official Publications of the European Communities, Luxembourg.

Fleury-Bahi, G., and Marcouyeux, A. (2011). "Evaluer la satisfaction envers l'espace de travail: Développement d'une échelle et première validation," ePTO. 27.

Glass, D. C., Reim, B., and Singer, J. E. (1971). "Behavioral consequences of adaptation to controllable and uncontrollable noise," J. exp. Soc. Psychol. 7, 244-257.

Grosjean, V., Kop, J., Formet-Robert, N., and Parmentier, C. (2008). "Un questionnaire d'évaluation de la santé au travail pour la prévention, le diagnostic et l'intervention - Manuel d'utilisation," Les Notes Scientifiques et Techniques de 1'INRS. 272, $39 \mathrm{p}$.

Jensen, K. L., Arens, E., Zagreus, L. (2005). “Acoustical quality in office workstation, as assessed by occupant surveys," Proceedings, Indoor Air 2005, pp 2401-2405.

Kjellberg, A., Landström, U., Tesarz, M., Soederberg, L., and Akerlund, E. (1996). "The effects of nonphysical noise characteristics, ongoing task and noise sensitivity on annoyance and distraction due to noise at work," J. Environ. Psychol. 16(2), 123-136.

Landström, U., Akerlund, E., Kjellberg, A., and Tesarz, M. (1995). "Exposure levels, tonal components and noise annoyance in working environments," Environ. Inter. 21, 265-275.

Leather, P., Beale, D., and Sullivan, L. (2003). "Noise, psychosocial stress and their interaction in the workplace," J. Exp. Psychol. 23, 391-397.

Lindvall, T., and Radford, T. P. (1973). "Measurement of annoyance due to exposure to environmental factors," Environ. Research. 6, 1-36.

Miedema, H. M., and Vos, H. (1998). "Exposure-response relationships for transportation noise," J. Acoust. Soc. Am. 104, 34323445 .

Pejtersen, J., Allermann, L., Kristensen, T. S., and Poulsen, O. M. (2006). "Indoor climate, psychosocial work environment and symptoms in open-plan offices," Indoor Air. 16, 392-401.

Schutte, M., Marks, A., Wenning, E., and Griefahn, B. (2007). "The development of the noise sensitivity questionnaire," Noise and Health. 9(34), 15-24.

Schutte, M., Sandrock, S., and Griefahn, B. (2007). "Factorial validity of the noise sensitivity questionnaire," Noise and Health. 9(37), 96-100.

Griefahn, B. (2008). "Determination of noise sensitivity within an internet survey using a reduced version of the Noise Sensitivity Questionnaire,” J. Acoust. Soc. Am. 123(5), 3449-3449. 